\title{
Çocuklarda demir eksikliği anemisinin tiroid hormonları üzerine etkisi
}

\section{The effect of iron deficiency anemia on thyroid hormones in the child}

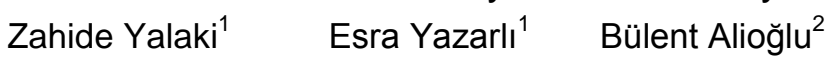 \\ ${ }^{1}$ Sağlık Bakanlığı Ankara Eğitim ve Araştırma Hastanesi, Çocuk Sağlığı ve Hastalıkları Kliniği, Ankara, \\ Türkiye \\ ${ }^{2}$ Sağlık Bakanlığı Ankara Eğitim ve Araştırma Hastanesi, Çocuk Sağlığı ve Hastalıkları Kliniği, \\ Hematoloji Bölümü, Ankara, Türkiye
}

Öz

Amaç: Demir eksikliği anemisi ve tiroid hormonları arasındaki ilişkinin araştırıldığı erişkin ve çocuk çalışmaları az sayıdadır. Bu çalışmada çocuklarda sık görülen demir eksikliği anemisi ile tiroid hormonları arasındaki ilişkinin araştırılması amaçlandı.

Gereç ve Yöntem: Çalışmaya 6 ay-17 yaş arası toplam 102 çocuk (70 demir eksikliği anemisi olan grup ve 32 kontrol grubu) alındı. Tüm hastalardan tam kan sayımı, serum demiri, demir bağlama kapasitesi, ferritin ve tiroid hormonları için kan alındı. Çalışma için hastanemiz etik kurulundan onam alındı. Elde edilen veriler SPSS 15.00 programı kullanılarak değerlendirildi.

Bulgular: Çalışma grubunun ortanca yaşı 7.5 yaş ve \% 62.9'u kız idi, kontrol grubunun ortanca yaşı 6 yaş ve \% 65.6 ' k $ı$ idi. Çalışma grubu ile kontrol grubu arasında yaş ve cinsiyet açısından fark saptanmadı ( $>0.005)$. Çalışma grubunda TSH ortalaması $2.03 \pm 0.95 \mu \mathrm{lU} / \mathrm{mL}$, serbest T4 (ST4) ortalaması $1.09 \pm 0.21 \mathrm{ng} / \mathrm{dL}$, ve serbest T3 (ST3) ortalaması $3.25 \pm 0.68 \mathrm{pg} / \mathrm{dL}$ iken, kontrol grubunda TSH ortalaması $2.15 \pm 0.94 \mu \mathrm{lU} / \mathrm{mL}$, ST4 ortalaması $1.14 \pm 0.16$ $\mathrm{ng} / \mathrm{dL}$, ST3 ortalaması $3.45 \pm 0.56 \mathrm{pg} / \mathrm{dL}$ idi ve istatistiksel olarak anlamlı fark saptanmadı (sırasıyla $p=0.540, p=0.255$, $p=0.149)$. Ancak ST4 ile hemoglobin arasında pozitif korelasyon saptandı $(p=0.031, r=0.214)$.

Sonuç: Çalışmamızda hemoglobin ile ST4 arasında pozitif korelasyon saptandı. Bu nedenle çocukluk çağında büyüme, bilişsel gelişimi ve zeka gelişiminde önemli olan demir ve tiroid hormonları arasındaki ilişkinin araştırılacağı daha geniş çaplı çalışmalara ihtiyaç olduğu düşünülmüştür.

Anahtar Sözcükler: Demir eksikliği anemisi, tiroid hormonu, çocuk.

\section{Abstract}

Aim: There are few studies that investigate the relationship between iron deficiency anemia and thyroid hormones. The aim of this study is to evaluate the relationship between iron deficiency anemia, a common disease of childhood, and thyroid hormones.

Materials and Methods: A total of 102 children (70 in the study group and 32 in the control group) ranging in age from 6 months to 17 years were included in the study. Blood samples were obtained from the children to determine total blood count, blood iron, total iron binding capacity, ferritin, and thyroid hormone levels.

Results: The median age of the study group was 7.5 years and $62.9 \%$ of the subjects were female. Gender and age distribution of the groups were not different ( $p>0.005)$. The mean thyroid-stimulating hormone (TSH) level was $2.03 \pm 0.95 \mu \mathrm{lU} / \mathrm{mL}$, mean free thyroxine (FT4) was $1.09 \pm 0.21 \mathrm{ng} / \mathrm{dL}$, and mean free triodothyronine (FT3) was $3.25 \pm 0.68 \mathrm{pg} / \mathrm{dL}$ in the study group. In the control group, mean TSH was $2.15 \pm 0.94 \mu / U / \mathrm{mL}$, mean FT4 was $1.14 \pm 0.16 \mathrm{ng} / \mathrm{dL}$, and mean FT3 was $3.45 \pm 0.56 \mathrm{pg} / \mathrm{dL}$. There was no statistically significant difference between the groups in TSH, FT4, or FT3 levels ( $p=0.540, p=0.255$, and $p=0.149$, respectively). However, there was a positive correlation between FT4 and hemoglobin ( $p=0.031, r=0.214)$.

Yazışma Adresi: Zahide Yalaki

Sağlık Bakanlığı Ankara Eğitim ve Araştırma Hastanesi, Çocuk

Sağlığı ve Hastalıkları Kliniği, Ankara, Türkiye

Makalenin Geliş Tarihi: 27.06.2016 Kabul Tarihi: 11.07.2016 
Conclusion: The main finding of our study was the positive correlation between FT4 and hemoglobin. Thus, we believe that further studies are needed to investigate the relationship between iron and thyroid hormones, which play important roles in growth and cognitive and mental development in childhood.

Keywords: Iron deficiency anemia, thyroid hormone, child

\section{Giriş}

Demir eksikliği (DE), ülkemizde ve tüm dünyada sık rastlanan besinsel eksiklik olup özellikle gelişmekte olan ülkelerde ve düşük sosyoekonomik koşullarda yaşayanlar için önemli bir halk sağlığı sorunudur $(1,2)$. Demir eksikliği anemisinin (DEA) halen dünya üzerinde 500 milyondan fazla kişiyi etkilediği düşünülmektedir (3). Ülkemizde Dünya Sağlık Örgütü'nün 2001 verilerine göre okul öncesi çocukların \%32.6'ında DEA bulunmaktadır (4). Demir vücudumuzda tüm hücreler için gerekli bir element olduğu için eksikliğinde büyüme, psikomotor gelişim, zihinsel gelişim, immün sistem, gastrointestinal sistem ve termoregülasyon da etkilenmektedir (5). Daha çok hayvan deneyleri ve erişkinlerde yapılan çalışmalarda demir eksikliğinden tiroid hormonlarının da etkilendiği bildirilmektedir (6-8).

Çocukların gelişiminde tiroid hormonları da önemli bir rol oynamaktadır. Normal tiroid fonksiyonları, süt çocukluğu ve çocukluk çağında normal somatik gelişme, beyin gelişimi ve büyüme için çok önemlidir. Tiroid hormonları, protein sentezi, su ve iyon transportu, termogenezis gibi olaylarda da rol alır (9). Bununla birlikte tiroid fonksiyonları akut veya kronik hastalıklar, postoperatif dönem, stres, ilaç kullanımları gibi durumlardan etkilenmektedir (6).

DEA olan çocuklarda tiroid hormonlarının nasıl etkilendiğine dair az sayıda çalışma bulunmaktadır. Bu nedenle çalışmamızda, çocuklarda sık görülen demir eksikliği anemisi ile tiroid hormonları arasındaki ilişkinin araştırılması amaçlanmıştır.

\section{Gereç ve Yöntem}

Aralık 2011-Eylül 2011 tarihleri arasında Sağlık Bakanlığı Ankara Eğitim ve Araştırma Hastanesi, Çocuk Polikliniği ve Çocuk Hematoloji Polikliniğine başvuran 6 ay-17 yaş arasındaki toplam 102 çocuk çalışmaya alındı.

Prematüre doğum öyküsü, kronik sistemik hastalığı, hematolojik hastalığı ve ilaç kullanım öyküsü olanlar çalışmaya dahil edilmedi. Çalışmaya alınanlardan tam kan sayımı, serum demiri, demir bağlama kapasitesi, ferritin düzeyleri için kan alındı. Çocuk polikliniği ve çocuk hematoloji polikliniğine başvuran 1 yaş üstü hastalardan, hemoglobin $(\mathrm{Hb})$ ve hematokrit $(\mathrm{Hct})$ değerleri, yaş grubuna göre 2 standart sapma altında olan ve ferritin düzeyi $12 \mathrm{ng} / \mathrm{mL}$ altında olanlar demir eksikliği anemisi tanısı ile çalışma grubu olarak tanımlandı (10).
Çocuk polikliniğine genel kontrol amaçlı başvuran, hemogram, ferritin değerleri normal sınırlar içerisinde olan, tiroid fonksiyonlarını etkileyebilecek herhangi bir ilaç kullanım öyküsü, sistemik ve kronik hastalığı olmayan çocuklar kontrol grubu olarak tanımlandı. Demir eksikliği anemisi tanısı alan hastalarda ve kontrol grubunu oluşturan çocuklarda serum serbest T3 (ST3) ve serbest T4 (ST4) ve Tiroid stimulan hormon (TSH) düzeyleri çalışıldı.

Elde edilen veriler SPSS 15.00 programı kullanılarak bilgisayar ortamında değerlendirildi; $p<0.05$ için sonuçlar istatistiksel olarak anlamlı kabul edildi. Sürekli ve kesikli sayısal değişkenlerin dağılımının normale yakın olup olmadığı Kolmogorov Smirnov testiyle araştırıldı. Dağılımları normal olan sayısal değerler için $(\mathrm{Hb}, \mathrm{Htc}$, $\mathrm{TSH}, \mathrm{sT4}, \mathrm{sT3}$ ) tanımlayıcı istatistikler ortalama $\pm \mathrm{SD}$, dağılımları normalden farklı olanlar için (yaş, ferritin) ortanca (en küçük - en büyük) şeklinde verildi. Kategorik değişkenler için tanımlayıcı istatistikler olgu sayısı ve \% biçiminde gösterildi.

Gruplar arasında ortanca değerler yönünden farkın önemliliği Mann Whitney $U$ testi ile araştırıldı. Ortanca değerler arasındaki korelasyonu değerlendirmek için Spearman korelasyon testi uygulandı. Kategorik değişkenler Pearson'un ki-kare veya Fisher'in kesin sonuçlu ki-kare testiyle değerlendirildi.

Çalışma için hastanemiz etik kurulundan 14.12.2011 tarih ve 3703 karar numarası ile onam alındı. Hastaların ailelerinden yazılı onam alındı.

\section{Bulgular}

Çalışmaya alınan 102 çocuğun ortanca yaşı 6.5 yaş ( 6 ay-17 yaş) ve 65'i (\%63.7) kız, 37'si (\%36.3) erkekti. Yetmişi (\%68.6) anemisi olan grup, 32'si (\%31.4) kontrol grubunu oluşturmaktaydı. Çalışma grubunun 44'ü (\%62.9) kız ve ortanca yaşı 7.5 (6 ay-17 yaş) idi, kontrol grubunun 21'i kız (\%65.6) ve ortanca yaşı 6 (6 ay-17 yaş) idi. Her iki grup arasında yaş ve cinsiyet dağıımı açısından anlamlı fark yoktu (sırası ile, $p=0.392$, $\mathrm{p}=0.828$ ).

Tam kan sayımı değerleri incelendiğinde çalışma grubunda $\mathrm{Hb}$ ortalama değeri $8.8 \pm 1.5 \mathrm{~g} / \mathrm{dL}$, Hct ortalama değeri \%27.9 44.2 , ferritin ortanca değeri $3(0.5-11.2)$ $\mathrm{ng} / \mathrm{mL}$ idi. Kontrol grubunda ise $\mathrm{Hb}$ ortalama değeri $13.4 \pm 1.1 \mathrm{~g} / \mathrm{dL}$, Hct ortalama değeri $\% 39.0 \pm 3.4$, ferritin ortanca değeri 27.9 (12.1-60) ng/mL olarak bulundu. 
Çalışma ve kontrol grubunun TSH, ST3 ve ST4 düzeyleri normaldi. Çalışma grubunda TSH ortalaması $2.03 \pm 0.95$ (0.34-4.81) $\mu \mathrm{lU} / \mathrm{mL}$, ST4 ortalaması $1.09 \pm 0.21(0.27$ 1.52) $\mathrm{ng} / \mathrm{dL}$, ve ST3 ortalaması $3.25 \pm 0.68$ (1.19-4.92) $\mathrm{pg} / \mathrm{dL}$ iken, kontrol grubunda TSH ortalaması $2.15 \pm 0.94$ (0.95-4.73) $\mu \mathrm{lU} / \mathrm{mL}$, ST4 ortalaması $1.14 \pm 0.16(0.84-1.5)$ $\mathrm{ng} / \mathrm{dL}$, ST3 ortalaması $3.45 \pm 0.56(2.47-4.92) \mathrm{pg} / \mathrm{dL}$ olarak bulundu ve istatistiksel olarak anlamlı fark saptanmadı (sırasıyla $p=0.540, p=0.255, p=0.149$ ).

Çalışma grubunda $\mathrm{Hb}$ ile ST4 arasında pozitif korelasyon saptanırken $(p=0.031, r=0.214)$, TSH ve ST3 ile $\mathrm{Hb}$ arasında ilişki saptanmadı.

\section{Tartışma}

Dünya Sağlık Örgütü'nün verilerine göre anemi, özellikle gebe ve çocuklarda yaygın bir halk sağlığı sorunudur $(1,2)$. Dünya Sağlık Örgütü'ne göre bir ülkede anemi prevalansı \%5 ise sorun yoktur, \%5-19 arasında ise hafif, \%20-39 arasında ise orta, \%40 ise ağır bir halk sağlığı sorunu vardır (11). Nutrisyonel DE ve DEA en sık görülen anemi nedenidir. Ülkemizde DE ve DEA ile ilgili yapılan çalışmalarda anemi sıklığının \%14-30 arasında olduğu bildirilmiştir (12). Demir eksikliği ve DEA büyümenin hızlandığı dönemde daha sık görülür. Beslenme biçimi, sosyoekonomik durum, geçirilmiş enfeksiyonlar anemi gelişiminde etkilidir $(1,11)$. Demir vücudumuzda birçok enzimin yapısında ve fonksiyonunda yer alığı için eksikliği durumunda tüm sistemler etkilenmektedir. DEA, çocukların bilişsel gelişimlerini, zekalarını, büyümelerini olumsuz yönde etkiler. DEA gelişen çocukların tedavi edilseler bile 5-10 yıl sonra zeka katsayılarının anemi gelişmemiş çocuklardan daha düşük olduğu da bilinmektedir (13). Bazı çalışmalarda anemi gelişmeden de DE'nin çocuklarda zeka ve motor gelişim test değerlerini düşürdüğü bildirilmiştir $(14,15)$.

Tiroid hormonları da süt çocuğu ve çocukluk çağında normal somatik gelişim, büyüme, beyin gelişimi ve zihinsel fonksiyonların gelişimi için çok önemlidir. İlk olarak ratlarda yapılan tiroid hormonları ile DEA arasındaki ilişkinin araştırıldığı çalışmalarda T3 ve T4 değerleri bazı çalışmalarda normal $(8,16,17)$, bazı çalışmalarda düşük bulunmuştur $(18,19)$. Beard ve ark. (8) ratlar üzerinde yaptığı çalışmada TRH uyarı testine TSH ve prolaktin cevaplarının anemik grupta daha zayıf, T3 ve T4 cevabının ise anemik ve kontrol grubu arasında fark olmadığını bildirmişlerdir (8). Tang ve ark. (19) da ratlarda DEA'da periferik T4 $\rightarrow \mathrm{T} 3$ dönüşümünün yavaşlamasına ek olarak hipofiz dokusunda TSH düzeylerinin azaldığını göstermişlerdir (19).

Yapılan çalışmalarda soğuk çevreye bırakılan deney hayvanlarında serum TRH, TSH ve katekolamin düzeylerinde yükselme, T4 sekresyonunda ve periferik $\mathrm{T} 4 \rightarrow \mathrm{T} 3$ dönüşümünde artış gözlenmiştir $(16,18)$. Ancak DEA olan ratlarda bu artışın olmadığı gösterilmiştir $(16,17,19)$. DEA ile tiroid hormonları arasındaki ilişkinin araştııılı̆̆ı insan çalışmaları az sayıdadır. Martinez ve ark. (20) yapmış olduğu çalışmada da DEA olan insanların soğuk su banyosu sırasında normal termoregülasyonu sağlayamadıkları bildirilmiştir. Demirin tiroid hormonların sentezi, sekresyon ve periferik metabolizmaları üzerine etkileri olduğu ileri sürülmüştür $(16,17,20)$. Tiroid hormon sentezinin ilk basamaklarını katalizleyen tiroid peroksidaz enzimi hem içermektedir. Tiroid peroksidazın etkinliği için ferriprotoporfirin IX'a bağlı hem proteini gerekmektedir. Bu nedenle DEA'da tiroid hormon sentezinin de etkilendiği ileri sürülmektedir (21). Ancak Tienboon ve ark. (22) yaptıkları çalışmada DEA olan çocuklarda demir tedavisi öncesi ve sonrasında tiroid hormon düzeyleri arasında fark bulamadıklarını bildirmişlerdir.

Ülkemizde DEA ve tiroid hormonları arasındaki ilişkinin araştırıldığı ilk çalışma Gündüz ve ark. (23) tarafından yapılmıştır. DEA olan 21 hasta ve 11 kontrol grubundan oluşan 32 çocuğun ( 6 ay-15 yaş) dahil edildiği çalışmada DEA olan grubun bazal TT3, TT4 ve TSH düzeylerini kontrol grubuna göre anlamlı olarak yüksek bulmuşlardır. DEA olan gruba iki aylık demir tedavisi verilmiş sonrasında bakılan değerlerde TT3 düzeyi kontrol grubuna göre anlamlı olarak yüksek bulunmuştur. Ancak TSH ve TT4 düzeylerinde anlamlı fark saptamamışlardır (23).

Gökdeniz ve ark. (6) erişkinlerde yaptıkları çalışmada ise DEA olan hastalarda sekonder ve subklinik hipotiroidi saptadıklarını verilen demir tedavisi ile tiroid hormonlarındaki bu değişikliklerin normale döndüğünü bildirmişlerdir. Yazar ve ark. (7) yine erişkinlerde yaptıkları çalışmada DEA olan grupta ST3 ve ST4'ün kontrollere göre istatistiksel olarak anlamlı düşük olduğunu bildirmişlerdir. İki grup arasında TSH düzeylerinde fark saptanmamıştır. Hastalara verilen demir tedavisinden sonra DEA olan grupta ST3 ve ST4 düzeylerinde anlamlı artış saptanırken, TSH düzeyinde düşme saptanmıştır.

$\mathrm{Bu}$ konuda çocuklarda yapılan çalışmalar sınırlıdır. Tienboon ve ark. (22), 9 DEA olan çocuk ve 8 kontrol grubundan oluşan çocuklarda yaptığı çalışmada $\mathrm{TSH}$, ST3, ST4, TT3 ve TT4 düzeylerinde anlamlı fark saptamamıştır. Bu çalışmada üç yaş üstü hastalar çalışmaya alınmamış ve az sayıda olgu ile çalışılmıştır. Bizim çalışmamızda ise geniş bir yaş aralığındaki (6 ay17 yaş) 70 hasta, 32 kontrol grubu incelendi. Literatürde çalışmamızdakine benzer geniş yaş aralığını kapsayan çalışmaya rastlamadık.

Çalışma grubu ile kontrol grubu arasında ST3, ST4 ve TSH düzeyleri arasında anlamlı bir fark saptanmadı. Ancak ST4'ün $\mathrm{Hb}$ ile pozitif korelasyonu olduğu saptandı. İpek ve ark. (24) 1-14 yaş arası 90 hasta ve 38 kontrol grubunda yaptıkları çalışmada DEA olan grupta TT3 ve TT4 düzeylerinde anlamlı düşük bulunurken, ST3 ve ST4 arasında anlamlı fark bulunmamıştır. Başka bir çalışmada da 1-15 yaş grubunda TSH, TT3, TT4, ST3 
ve ST4 düzeylerinde anlamlı fark saptanmamıştır (25). Her iki çalışmada da yaş grupları birbirine benzerdir.

Yavuz ve ark. (26) okul çağı çocuklarında yapmış olduğu geniş bir grup çalışmasında (toplam 330) DEA olan ve olmayanlar arasında çalışmamızdakine benzer şekilde ST3, ST4 ve TSH düzeylerini karşılaştırmışlar ve iki grup arasında anlamlı fark saptamamışlardır (Tablo-1). Çalışmaya alınan vaka sayısı bizimkinden fazladır ancak sadece 12-14 yaş arası okul çağı çocuklarında yapılmıştır. Çalışmamızda ise daha geniş bir yaş aralığı çalışmaya dahil edilmiştir.

Tablo-1. Çalışma ve Kontrol Gruplarının Tirod Hormon Değerleri.

\begin{tabular}{lccc}
\hline & Hasta & Kontrol & p \\
\hline TSH & $2.03 \pm 0.95$ & $2.15 \pm 0.94$ & 0.540 \\
ST4 & $1.09 \pm 0.21$ & $1.14 \pm 0.16$ & 0.255 \\
ST3 & $3.25 \pm 0.68$ & $3.45 \pm 0.56$ & 0.149 \\
\hline
\end{tabular}

Literatürde erişkinlerde yapılan çalışmalarda DEA olan gruplarda hipotiriodiye rastlanabileceği ve bu durumun demir tedavisi ile kendiliğinden düzelebileceği bildirilmektedir $(6,7)$.
Çocuklarda yapılan çalışmalarda ise DEA ve hipotiroidi saptanan demir tedavisi verildikten sonra tekrar tiroid hormonlarına bakılan çalışmaya rastlanmadı. İpek ve ark. (24) yaptığı çalışmada DEA olan grupta TT4 ve TT3 düzeylerinde kontrollere göre anlamlı düşüklük saptanırken, ST3 ve ST4'de anlamlı fark bulunmamıştır. Bizim çalışmamızda TT3 ve TT4 düzeylerine bakılmamıştı, ST4 ve ST3 düzeylerinde de kontrole göre anlamlı fark bulunmadı. Ancak ST4 ile $\mathrm{Hb}$ arasında pozitif korelasyon saptandı. Vücudumuzda biyolojik olarak etkin olan ST4'ün hemoglobin düzeylerindeki değişikliklerden etkilenebileceği düşünüldü. Ancak benzer sonuç alınan başka bir çalışmaya rastlanmadığından karşılaştırma yapılamadı. Ülkemizde DEA halen sık olarak görüldüğü ve bu durumun çocuklarda büyümeyi, zeka gelişimini etkilemesinden dolayı; benzer şekilde tiroid hormonlarının da çocuklarda büyümeyi, bilişsel gelişimi ve zeka gelişimini etkilemesi bakımından DEA ve tiroid hormonları arasındaki ilişkinin aydınlatılması için daha geniş kapsamlı çalışmalara intiyaç olduğu düşünülmüştür.

\section{Kaynaklar}

1. Merovitch J, Sherf M, Antebi F, et al. The incidence of anemia in an Israeli population: A population analysis for anemia in 34 512 Israeli infants aged 9 to 18 months. Pediatrics 2006;118(4):1055-60.

2. Schneider JM, Fujii ML, Lamp CL, Lönnerdal B, Zidenberg-Cherr S. Anemia, iron deficiency and iron deficiency anemia in 1236mo-old children from low-income families. Am J Clin Nutr 2005;82(6):1269-75.

3. World McLean E, Cogswell M, Egli I, de Benoist B. Worldwide prevalence of anaemia, WHO Vitamin and Mineral Nutrition Information System, 1993-2005. Public Health Nutr 2009;12(4):444-54.

4. Iron deficiency anemia: assessment, prevention and control. A guide for programme managers. Geneva, World HealthOrganization, 2001 (WHO/NHD/01.3). Available from: http:/www.who.int/nutrition/ publications/ micronutrients/ anaemia iron deficiency/WHO NHD 01.3/en/index.html

5. Prasad AN, Prasad C. Iron deficiency; non-hematological manifestations. Prog Food Nutr Sci 1991;15(4):255-83.

6. Gökdeniz E, Demir C, Dilek İ. Demir eksikliği anemisinin tiroid fonksiyonları üzerine etkisi J Clin Exp Invest 2010;1(3):156-60.

7. Yazar A, Pata C, Altıntaş E, Kıykım AA, Gen R, Polat G. Demir eksikliği anemisi ve demir tedavisinin plazma tiroid hormon düzeylerine etkisi. İstanbul Tıp Fakültesi Dergisi 2002;65(2):125-8.

8. Beard J, Tobin B, Gren W. Evidence for the thyroid hormone deficiency in iron deficient anemic rats. J Nutr 1989;119(9):772-8.

9. Kelnar CJH, Butler GE. The thyroid gland. In: Mc Intosh N, Helms P, Smyth R, (eds). Forfar and Arneil's Textbook of Pediatrics 6th edition Elsevier Livingstone, 2003;506-14.

10. Soycan LY. Çocukta anemiye yaklaşım: sınıflama ve ayırıcı tanı. İ.Ü.Cerrahpaşa Tıp Fakültesi Sürekli Tıp Eğitimi Etkinlikleri Anemiler sempozyumu İstanbul 2001;127-35.

11. Andrews NC, Bridges KR. Disorders of iron metabolism. Nathan and Oski's Hematology of Infancy and Childhood Vol I (5th ed). Philadelphia: WB Saunders, 1998:437-42.

12. Kutluay MT, Köksal G, Köksal E. Nutritional status and problems of school age children in Turkey. Hacettepe University, Department of Nutrition and Dietetics, Ankara, Turkey, 2006. Available from: http://www.gcnf.org/library/countryreports/turkey/2006-Turkey-Nutrition-Status-Problems.pdf.

13. Lannotti LL, Tielsch JM, Black MM, Black RE. Iron supplementation in early childhood: Health benefits and risks. Am J Clin Nutr 2006;84(6):1261-76.

14. Berrak SG, Türkan E, Canbolat C, Kahveci S. Çocuklardaki demir eksikliği tedavisinin düşük gelişim test skorlarına etkisi. İstanbul Tıp Fakültesi Mecmuası 2002;65(3):188-96.

15. Ağaağlu L, Torun O, Sefil Y, Demir D, Ünüvar E. Demir eksikliği anemisi ve zeka üzerine etkisi. Çocuk Dergisi 2004;4(4):241-7.

16. Dillman E, Gale C, Green W, Johnson DG, Mackler B, Finch C. Hypothermia in iron deficiency due to altered triiodothyronine metabolism. Am J Physiol 1980;239(5):377-81.

17. Beard J, Tobin B, Smith SM. Effects of iron repletion and correction of anemia on norepinephrine turnover and thyroid metabolism in iron deficiency. Proc Soc Exp Biol Med 1990;193(4):306-12.

18. Beard J. Feed efficiency and norepinephrine turnover in iron deficiency. ProcSoc Exp Biol Med 1987;184(3):337-44.

19. Tang F, Wong TM, Loh TT. Effects of cold exposure or TRH on the serum TSH levels in the iron deficient rat. Horm Metab Res $1988 ; 20(10): 616-9$. 
20. Martinez-Torres C, Cubeddu L, Dillman E, et al. Effect of exposure to low temperature on normal and iron deficient subjects. Am J Physiol 1984;246(3):380-3.

21. Zimmermann M, Adou P, Torresani T, Zeder C, Hurrell R. Persistence of goiter despite oral iodine supplementation in goitrous children with iron deficiency anemia in Côte d'Ivoire. Am J Clin Nutr 2000;71(1):88-93.

22. Tienboon P, Unachak K. Iron deficiency anemia in childhood and thyroid function. Asia Pac J Clin Nutr 2003;12(2):198-202.

23. Gündüz Z, Kumandaş S, Kurtoğlu S, Üzüm K. Demir eksikliği anemisinin tiroid hormonları üzerine etkileri. Turk J Med Res 1992;10(4):205-9.

24. Ipek IÖ, Kaçmaz E, Bozaykut A, Sezer RG, Seren L, Paketci C. Çocukluk çağında demir eksikliği anemisinin plazma tiroid hormonları üzerine etkisi. Türk Ped Arş 2011;46(2):129-32.

25. Demir F, Yükselmiş U, Sarı MY, Korkmaz G, Türkkan E, Adal SE. Demir eksikliği anemisinin tiroid hormonları üzerine etkileri. Abant Med J 2013;2(1):1-6.

26. Yavuz O, Yavuz T, Kahraman C, Yeşildal N, Bundak R. The Relationship between iron status and thyroid hormones in adolescents living in iodine deficient area. J Pediatr Endocrinol Metab 2004;17(10):1443-9. 